\title{
KOSAKATA DALAM KARANGAN NARASI MURID SEKOLAH DASAR UNTUK BAHAN PENGAJARAN MEMBACA (Kajian Leksikologi dan Psikolinguistik)
}

\author{
Leli Salimatul Hapsah \\ Prodi Pendidikan Bahasa dan Budaya Sunda Sekolah Pascasarjana - UPI \\ Posel: leli_sh28@yahoo.co.id
}

\begin{abstract}
Abstrak
Prinsip pengajaran bahasa yaitu mengajarkan murid terampil berbahasa. Kuantitas dan kualitas keterampilan berbahasa dapat dilihat dari kuantitas dan kualitas kosakata yang dikuasai. Kurangnya penelitian mengenai kosakata murid sekolah dasar menjadi landasan pelaksanaan penelitian ini. Tujuan pelaksanaan penelitian yaitu untuk mengetahui dan mendeskripsikan tiga hal yaitu jenis kosakata dalam karangan narasi murid sekolah dasar, kesesuaian kosakata dengan perkembangan umur murid sekolah dasar, dan karangan narasi yang dapat dijadikan bahan pengajaran membaca. Penelitian ini menggunakan pendekatan kualitatif. Metode penelitian yang digunakan yaitu metode deskriptif. Teknik analisis data menggunakan teknik analisis unsur langsung. Dari 16 karangan ditemukan 650 kata dengan frekuensi penggunaan sebanyak 2520 kata. Setelah dilakukan analisis terhadap jenis kosakata ditemukan data kata dasar sebanyak 216, bentukan kata baru sebanyak 126 kata, dan kata tugas sebanyak 74 kata. Dari karangan narasi yang ditulis oleh murid sekolah dasar relatif sesuai dengan perkembangan umur murid. Hal ini dapat dilihat dari 650 kata hanya 10 kata yang dianggap termasuk kata - kata untuk penutur dewasa. Dari 16 karangan yang ditulis murid sekolah dasar terdapat 5 karangan yang dianggap sesuai untuk bahan pengajaran membaca dilihat dari tingkat interferensi dan alur karangan narasi.
\end{abstract}

Kata kunci: Kosakata, Murid Sekolah Dasar, Bahan Pengajaran Membaca.

\section{VOCABULARIES IN ELEMENTARY STUDENTS' NARRATIVE TEXT FOR READING TEACHING MATERIALS (Lexicology and Psycholinguistic Study at SDN Galunggung, Tawang District Tasikmalaya City}

\begin{abstract}
The principle of language teaching is to teach students to achieve their language skills. The quantity and quality of language skills can be seen from the quantity and quality of the vocabulary mastery. The lack of research on the vocabulary of elementary school students is the background of this research. The purposes of the research are to identify and describe three things i.e. the type of vocabulary in the elementary school students'narrative essay, the suitability of vocabulary with the age development of elementary school students, and narrative essay that can be used as reading teaching material. This research used qualitative approach. Research method used is descriptive method. Data analysis technique employed is direct element analysis technique. In 16 articles, there are found 650 words with 2520 words usage frequency. After the vocabulary type analysis, it was found that the root words data are 216, the formation of new words are 126 words, and the word task are 74 words. The result
\end{abstract}


showed that the narrative written by elementary school students is relatively in accordance with the students' age development. This can be seen from 650 words only 10 words that are considered as the words for adult speakers. In 16 essays written by elementary school students, there are 5 essays that are considered appropriate for reading teaching material based on the level of interference and narrative essay.

Keywords: Vocabulary, Elementary School Student, Reading Teaching Material.

\section{PENDAHULUAN}

Prinsip pengajaran bahasa adalah agar murid terampil berbahasa. Keterampilan berbahasa meliputi menyimak, berbicara, membaca, dan menulis. Kuantitas dan kualitas keterampilan berbahasa seseorang dapat dilihat dari kuantitas dan kualitas kosakata yang dimiliki (Tarigan, 2011, hlm. 2). Kosakata mampu membawa murid memasuki pengalaman-pengalaman yang lebih luas. Dalam pengajaran kosakata di sekolah murid mempelajari kata dan makna kata tersebut. Pertama, murid menemukan kata baru dan mencari makna katanya. Setelah mengetahui makna dari suatu kata, murid akan belajar menerapkannya dalam kehidupannya sehari-hari.

Perkembangan kosakata erat hubungannya dengan perkembangan mental konseptual. Kosakata dan kemampuan mental menunjukkan hubungan kausalitas. Kualitas dan kuantitas kosakata menentukan kualitas kemampuan mental murid.

Pengajaran kosakata, khususnya di sekolah dasar terpadu dalam pengajaran keterampilan bahasa. Berdasarkan data empiris pengajaran di sekolah dasar, banyak ditemukan masalah dalam pengajaran bahasa Sunda terkait kosakata. Sebagian murid tidak mengetahui makna kata-kata dalam teks yang terdapat pada buku teks. Hal ini mengakibatkan murid mengalami kesulitan dalam menjawab pertanyaan - pertanyaan dalam tugas sekolahnya. Selain itu, murid tidak lancar membaca teks dan tidak memahami arti dari kata-kata yang dibacanya.
Kemampuan kosakata erat hubungannya dengan keterampilan membaca. Salah satu faktor yang membuat membaca menjadi sulit adalah keterbatasan kosakata. Karangan narasi yang ditulis oleh murid sekolah dasar dapat menjadi alternatif bahan pengajaran membaca.

\section{METODE}

Penelitian ini dilaksanakan dengan menggunakan pendekatan kualitatif. Metode yang digunakan yaitu metode deskriptif. Analisis data dalam kualitatif bersifat induktif. Menurut Guba dan Lincoln (1985, hlm. 39-43) dalam Alwasilah (2002, hlm.105) salah satu karakteristik penelitian kualitatif, analisis data dilakukan secara induktif.

Metode induktif dipilih ketimbang metode deduktif karena metode ini lebih memungkinkan peneliti mengidentifikasi realitas yang berbagai-bagai di lapangan, membuat interaksi antara peneliti dan responden lebih eksplisit, nampak, dan mudah dilakukan; dan memungkinkan identifikasi aspek-aspek yang saling mempengaruhi. ( Guba dan Lincoln, 1985; Alwasilah: 2002).

Langkah-langkah penelitian yang dilakukan yaitu menentukan masalah kemudian melakukan studi pendahuluan untuk mendapat informasi awal kemudian selanjutnya adalah merumuskan masalah. Instrumen penelitian dibuat karena peneliti mulai memasuki situasi sosial dalam penelitian. Selanjutnya peneliti melakukan reduksi terhadap semua data yang ada untuk dianalisis diakhiri dengan membuat 
kesimpulan. Setelah semua selesai peneliti kemudian menyusun laporan penelitian.

Data penelitian berupa karangan narasi. Sumber data penelitian yaitu murid kelas IV SDN Galunggung Kecamatan Tawang Kota Tasikmalaya. Teknik pengumpulan data yang dilakukan yaitu teknik tes dan teknik dokumentasi.

\section{HASIL DAN PEMBAHASAN}

Jenis Kosakata dalam Karangan Narasi Murid SD

Penelitian ini dilaksanakan di SDN Galunggung Kota Tasikmalaya. Penelitian dilakukan di kelas IV. Tema karangan yaitu cita-cita. Setelah dilakukan analisis, dari 16 karangan narasi murid sekolah dasar, ditemukan data kata sebanyak 650 kata yang frekuensi pemakaianya sebanyak 2520 kata. Jenis kosakata yang ditemukan dalam data penelitian meliputi (1) kosakata dasar, (2) bentukan kata baru, (3) kata tugas.

Kosakata dasar merupakan kata-kata yang tidak mudah berubah dan sedikit kemungkinan diambil dari bahasa lain (Tarigan, 2011, hal. 3). Dari hasil penelitian ditemukan tujuh jenis kata dasar yaitu (1) istilah kekerabatan, (2) istilah anggota badan, (3) kata ganti (pronomina), (4) kata bilangan (numeralia), (5) kata kerja (verba), (6) kata sipat (adjektiva), dan (7) kata benda (nomina).

Istilah kekerabatan menunjukan hubungan kekeluargaan. Seperti hubungan orang tua (ayah ibu) dan anak. Dari hasil analisis data ditemukan 17 kata yang menunjukan istilah kekerabatan. Contoh istilah kekerabatan seperti berikut.

1. (017) A Apit (K14/P04/KL01)

2. (019) aa (K01/P02/KL02)

3. (027) ade (K04/P02/KL04)

4. (074) bapa (K01/P01/KL05)

5. (106) bunda (K17/P01/KL04)

Dari data di atas jelas kata-kata tersebut termasuk ke dalam istilah kekerabatan. Kata $a a$ digunakan untuk menyebut kakak laki-laki dalam bahasa
Sunda. Biasanya untuk memanggil personalnya menggunakan nama seperti $A$ Agung. Kata bunda termasuk kata yang mengalami interferensi dari bahasa Indonesia.

Istilah anggota badan merupakan kata-kata yang menunjukan atau menyebutkan anggota badan. Dari hasil analisis ditemukan 1 kata yang menunjukan istilah anggota badan, yaitu kata patuangan (K08/P01/KL11).

Kata ganti dipakai untuk mengganti kata benda yang menunjukan orang. Dari hasil analisis terdapat 5 kata ganti. Seperti data di bawah ini

1. (021) abdi (K10/P01/02)

2. (022) abdina (K03/P02/KL03)

3. (023) abi (K10/P03/01)

4. (054) arurang (K16/P07/KL01)

5. (628) urang (K04/P04/KL02)

Dari data di atas terlihat kata ganti seperti abdi, abdina, urang, dan arurang. Kata ganti di atas termasuk kta ganti orang pertama. Kata abdi, abdina, dan abi termasuk kata ganti orang pertama tunggal. Sedangkan kata urang dan arurang termasuk kata ganti orang pertama jamak.

Kata bilangan merupakan kata yang menunjukan jumlah, urutan, dan tahapan dari benda. Kata bilangan dapat berupa kecap bilangan utama, acak, peahan, tahapan, dan klitik. Dari hasil analisis ditemukan 22 kata bilangan. Contoh kata bilangan dapat dilihat di bawah ini.

1. (001) 03.00 (K08/P02/KL13)

2. (013) 2 (K13/P01/KL02)

3. (241) kadua (K13/P01/KL02)

4. (528) sasasih (K15/P02KL/05)

5. (529) satengah (K11/P02/KL02)

Dari data di atas terlihat beberapa jenis kata bilangan. Bilangan 2 menunjukan bilangan utama. Bilangan 03.00 termasuk bilangan utama yang menunjukan waktu. Kata bilangan kadua termasuk kata bilangan tahapan. Kata bilangan sasasih dan satengah termasuk kata bilangan pecahan. 
Kata kerja adalah kata yang umumnya memiliki fungsi predikat dalam kalimat (Sudaryat, 2007, hlm. 87). Dari hasil analisis terdapat 113 kata. Contoh kata kerja dalam karangan narasi murid sekolah dasar dapat dilihat di bawah ini.

1. (045) Basa abi angkat ka sakola (K01/P01/KL07)

2. (050) Améh apal tentang cara menilang motor (K15/P02/KL11)

3. (071) Kedah getol balajarna, entong maen game (K01/P02/KL06)

4. (139) Unggal dinten abdi sakola dianterkeun bapa (K05/P02/KL02)

5. (189) Abdi mah sok guntas-gentos cita-citana (K07/P01/KL03)

Kata sipat kata yang memiliki arti bawaan dan keadaan. Biasanya menunjukan ciri benda. Dari hasil analisis ditemukan 60 kata. Di bawah ini contoh kata kerja dalam karangan narasi murid sekolah dasar.

1. (040) Soalna mobil alus pisan (K02/P01/KL05)

2. (084) Engke teh bisi janten belet (K10/P02/KL03)

3. (092) Dina mobilna abdi hoyong warna beureum (K02/P02/KL06)

4. (107) Meh caket wargi (K07/P04/KL08)

5. (110) Téh Agung téh meni cantik (K14/P04/KL04)

Kata benda merupakan kata yang menunjukan benda atau yang dianggap benda. Ciri kata benda yaitu menandai satu benda yang dapat berdiri sendiri dalam kalimat dan tidak tergantung pada bentuk kata yang lain. Dari hasil analisis ditemukan 293 kata benda. Contoh kata benda dalam karangan narasi murid sekolah dasar dapat dilihat dibawah ini.

1. (019) aa (K01/P02/KL02)

2. (021) abdi (K10/P01/02)

3. (025) acuk (K08/P01/KL10)

4. (268) kieu (K01/P02/KL06)

5. (280) kumaha (K05/P08/KL01)

Dari data di atas terdapat beberapa jenis kata benda. Kata $a a$ termasuk kata sebutan. Kata aa biasanya dipakai untuk menyebut kakak laki-laki. Kata abdi termasuk kata ganti. Kata acuk termasuk kata benda mati. Kata kieu termasuk kata tunjuk yang menunjukan hal/cara. Kata kumaha termasuk kata tanya.

Bentukan kata baru merupakan kata serapan atau kata yang diambil dari bahasa asing. Dari hasil analisis ditemukan 74 kata yang termasuk bentukan kata baru. Contoh bentukan kata baru dapat dilihat pada data di bawah ini.

1. (048) an-naziat (K14/P02/KL05)

2. (071) balajarna (K01/P02/KL06)

3. (073) bangun (K08/P01/KL07)

4. (113) catering (K05/P01/KL03)

5. (117) chef (K07/P01/KL04)

Dari data di atas terdapat beberapa kata yang termasuk bentukan kata baru. Kata-kata tersebut mengalami interferensi dari bahasa Indonesia, bahasa Inggris, dan bahasa Arab. Kata an - naziat merupakan kata serapan dari bahasa Arab. Kata balajarna dan bangun merupakan serapan dari bahasa Indonesia. Kata chef dan catering merupakan serapan dari bahasa Inggris.

Kata tugas memiliki fungsi sebagai alat dalam kalimat. Dapat menambahkan, mengaitkan, dan menyambungkan kalimat. Dari hasil analisis ditemukan kata tugas sebanyak 126 kata. Berikut beberapa contoh kata tugas.

1. (126) da (K02/P01/KL03)

2. (329) meni (K14/P04/KL04)

3. (354) mung (K13/P03/KL02)

4. (059) atos (K01/P02/KL01)

5. (093) bisa (K03/P01/KL06)

6. (041) ambéh (K16/P05/KL02)

7. (020) aammiinn (K14/P05/KL06)

Dari data - data di atas tampak kosakata dalam karangan narasi yang ditulis oleh murid kelas IV SD. Ditemukan data bahwa kata benda lebih banyak diperoleh dibanding kata kerja dan katakata lainnya. Hal ini sesuai dengan penelitian sebelumnya mengenai kosakata bahasa Indonesia di kelas II SD. Dari 
penelitian yang pernah dilakukan oleh Nurita Bayu Kusmayati baawa kemampuan menulis dalam bentuk kalimat tunggal kategori kalimatnya berupa kalimat verbal karena kata yang berfungsi sebagai predikat berupa verba. Sedangkan nomina tersebar sebagai subjek atau objek kalimat. Oleh karena itu, murid lebih menguasai nomina dibanding verba. Berkaitan dengan hal ini, para ahli memiliki pandangan masing-masing. Bloom dan Tandif menjelaskan bahwa murid lebih awal menguasai verba daripada nomina. Sedengkan Gentner sebaliknya. Gentner menjelaskan bahwa murid menguasai nomina lebih awal dan lebih banyak jumlahnya (Kusmayati, 2009, hlm. 201).

Dari karangan narasi yang ditulis oleh murid sekolah dasar ada dua persoalan yaitu cara penulisan kata-kata serta persoalan interferensi. Persoalan cara penulisan banyak ditemukan dalam setiap karangan. Contohnya seperti cara penulisan kata-kata berikut.

1. (528) Seer pisan (K01/P03/KL07)

2. (529) ulah seeur melid (K10/P02/KL01)

3. (535) Bapa Fisca seueur mobil (K05/P01/KL04)

Kata-kata di atas adalah kata tugas yang memiliki makna yang sama. Tapi dalam karangan kata tersebut ditulis berbeda. Kata yang benar penulisnnya adalah kata pada nomor 3. Hal ini menginformasikan bawa murid sekolah dasar masih belum bisa menuliskan katakata dengan benar. Murid belum bisa menuliskan kata-kata yang mengandung unsur vokal e, é, dan eu.

Persoalan interferensi juga

ditemukan dalam karangan narasi. Interferensi yang ditemukan yaitu interferensi bahasa Indonesia, bahasa Inggris, dan bahasa Arab. Interferensi bahasa Indonesia muncul karena beberapa kemungkinan. Pertama, keluarga murid bukan penutur asli bahasa Sunda. Baik ibu maupun ayah. Jadi bahasa yang dipergunakan sehari-hari bukan bahasa Sunda. Kedua, salah satu orang tua murid bukan orang Sunda yang akhirnya komunikasi tidak menggunakan bahasa Sunda. Ketiga, kedua orang tua murid berasal dari Sunda tapi sehari-hari komunikasi lebih sering menggunakan bahasa Indonesia ketimbang bahasa Sunda. Karena beberapa hal tadi, murid hanya mendapat pengalaman belajar bahasa Sunda hanya di sekolah atau lingkungan di sekitarnya yang tidak menjamin pemakaiannya benar dan akhirnya murid seringkali mendapatkan kosakata yang tidak tepat atau bahasa Sunda yang kasar.

$$
\text { Perkembangan teknologi, }
$$

komunikasi, dan informasi dapat menjadi salahsatu faktor munculnya interferensi bahasa Inggris. Saat ini game-game online sangat mudah diakses oleh murid. Istilahistilah asing dapat masuk melalui acara tv, iklan, dan program-program hiburan lainnya. Anggapan mengahadapi globalisasi bisa jadi pangaruh untuk masyarakat bahwa menggunakan bahasa Inggris lebih baik ketimbang menggunakan bahasa Sunda. Banyak murid yang mengikuti les bahasa Inggris. Hal ini tidak berarti murid tidak boleh belajar bahasa Inggris tapi perlu disadari bahwa bahasa Sunda juga penting. Ada peribasa mengatakan bahwa bahasa adalah ciri bangsa. Hilangnya bahasa berarti hilang pula bangsanya. Murid perlu menguasai bahasa ibunya agar kemudian tidak bingung menguasai struktur bahasa asing yang dipelajari.

Interferensi bahasa Arab yang ada dalam karangan narasi murid sekolah dasar muncul karena sistem pendidikan di lingkungan keluarga. Hal ini muncul dalam karangan narasi yang ditulis oleh murid. Kata-kata seperti an - naziat, Daarul Ilmi Cendekia, umroh, dan solat termasuk kata yang terpengaruh dari bahasa Arab. Kata Daarul Ilmi Cendekia menunjukan tempat. Daarul Ilmi Cendekia merupakan tempat 
belajar ilmu agama atau berupa madrasah diniyah awaliyah yan di masyarakat umumnya disebut sekolah agama. Hal ini menunjukan pendidikan agama menjadi dasar pendidikan dalam keluarga. Selain itu, kata solat di masyarakat biasanya memiliki beberapa variasi seperti kata netepan dan Alloh. Kata netepan biasa digunakan baik oleh orang tua maupun oleh anak-anak. Kata Alloh biasanya digunakan oleh orang tua untuk membahasakan solat kepada anakanaknya.

\section{Kesesuaian Kosakata dengan Perkembangan Umur Murid SD}

Psikolinguistik yaitu teori linguistik berdasarkan bahasa yang dianggap sebagai satu elemen yang saling mempengaruhi. Menurut teori pengajaran behaviorisme, psikolinguistik merupakan teori pengajaran bahasa sebagai satu sitem tabiat dan kemampuan yang menghubungkan isarat dengan tingkah laku.

Teori psikolinguistik erat hubungannya dengan pengajaran bahasa. Psikolinguistik memiliki tiga fokus yaitu language acquisition, language learning dan language teaching. Oleh karena itu, segala persoalan yang berhubungan dengan tiga fokus tadi masuk dalam kajian psikolinguistik. Language acquisition berhubungan dengan bahasa ibu, sedangkan language learning berhubungan dengan pengajaran bahasa kedua.

Menurut Piaget dan Vygotsky (dalam Resmini, 2006, hlm. 13), perkembangan bahasa murid terdapat beberapa tahapan. Dalam umur lima tahun ke atas, murid sudah memiliki kompetensi penuh. Artinya murid umur sekolah dasar (6 - 12 tahun) sudah memiliki keterampilan dalam komunikasi meskipun masih memerlukan bimbingan dari guru dan lingkungan sekitar.

A sytematic program of vocabulary mastery helps the student develop a flexible mental file for storing and retrieving words. A new words isn't of much value if it is filed and lost. So a mental filing system must be active. This mental file can become a lightning - fast computer to help remember and figure out the meaning of word (Dale, 1971, hlm. 7).

Program kosakata yang disusun secara sistemis akan meningkatkan kemampuan mental untuk menguasai dan menggunakan lagi kata-katanya. Kata-kata baru tidak akan memberi manfaat kalau hanya dihafal dan kemudian lupa. Oleh karena itu, sistem mental harus aktip. Karena kemampuan mental bisa jadi alat yang sangat berguna untuk mengingat serta menjelaskan makna kata.

Dari hasil analisis data ditemukan 650 kata yang frekuensi pemakaiannya sebanyak 2520 kata dapat dilihat bahawa kata-kata yang digunakan murid kelas IV SD N Galunggung Kota Tasikmalaya relatif sesuai dengan perkembangan umurnya. Hal ini terbukti dari 650 kata terdapat 640 kata $(98,46 \%)$ yang umumnya digunakan oleh murid kelas IV sekolah dasar. Sisanya terdapat 10 kata $(1,54 \%)$ termasuk dalam kata-kata untuk penutur dewasa seperti kata bogoh, calon, calég, dan modif. Kata-kata tersebut termasuk kata-kata untuk penutur dewasa karena sering digunakan untuk penutur dewasa. Selain itu, kata-kata tersebut memiliki arti kompleks dan erat hubunganya dengan kehidupan penutur dewasa.

Dari karangan narasi yang ditulis oleh murid dapat terlihat latar belakang murid dan kegiatan sehari-hari di keluarganya. Kata-kata tersebut dapat masuk dalam kosakata murid disebabkan beberapa hal. Latar belakang keluarga dan lingkungan murid mempengaruhi kosakatanya. Perkembangan teknologi dan komunikasi juga memberi pengaruh terhadap perkembangan kosakata murid.

Selain persoalan kata-kata yang tidak sesuai dengan perkembangan umur murid, terdapat juga kata-kata yang khas 
digunakan oleh murid atau termasuk katakata anak-anak. Berikut kata-kata yang khas digunakan anak-anak.

1. (163) emam (K04/P02/KL01)

2. (183) gén (K05/P07/KL02)

3. (329) meni (K14/P04/KL04)

4. (439) ongkohan (K16/P05/KL04)

5. (652) wén (K03/P02/KL04)

Kata-kata di atas adalah kata-kata yang khas digunakan anak-ana. Kata emam berasal dari kata dahar. Dalam bahasa Indonesia berarti makan. Kata gén, ongkohan, dan wén berasal dari kata ogé, ongkoh, dan wé. Kata meni seharusnya ditulis mani. Kata-kata tersebut sering digunakan murid sekolah dasar dalam kegiatan sehari-hari. Kata-kata tersebut sangat erat kaitannya dengan language acquisition. Kata emam biasanya digunakan orang tua untuk membahasakan makan kepada anak. Oleh karena itu, anak kemudian mengenal dan menggunakan kata emam.

\section{Karangan Narasi untuk Pengajaran Membaca}

Membaca dapat diartikan sebagai suatu metode komunikasi baik dengan diri sendiri maupun dengan orang lain. Dalam arti mengkomunikasikan makna yang ada pada lambang-lambang tertulis. Singkatnya, membaca yaitu memahami pola-pola bahasa dalam bentuk tertulis (Tarigan, 2008, hlm. 7).

Salah satu cara yang bisa dilakukan oleh guru untuk meningkatkan perkembangan keterampilan membaca yaitu dengan memperkaya kosa kata murid melalui cara mengajarkan sinonim, antonim, parafrase, dan kata-kata yang memiliki dasar sama, mengajarkan imbuhan yang meliputi awalan, sisipan, dan akhiran, mengira-ngira makna kata dari konteks atau hubungan kalimat, menjelaskan dengan menggunakan bahasa ibu arti dari kata-kata yang abstrak (Tarigan, 2008, hlm. 15).
Bahan ajar membaca berupa teks. Bahan ajar membaca yang dipilih harus sesuai dengan kriteria yaitu isi bahan ajar harus sesuai dengan tujuan khusus pengajaran, valid dan reliabel, susunan bahan ajar logis, isi bahan ajar bisa dipertanggungjawabkan, bahan ajar sesuai dengan bahan yang diajarkan, urutan kegiatan pengajarannya benar, dapat memberi kesan, meningkatkan perkembangan berpikir kritis, menggunakan pendekatan yang bisa mengoptimalkan panca indra, memiliki transfer value (Husen, 1996, hlm. 105).

Narasi adalah satu bentuk wacana yang sasaran utamanya berupa urutan tingkah laku yang diatur menjadi kejadian dalam waktu tertentu. Narasi juga dapat diartikan sebagai satu bentuk wacana yang menggambarkan secara jelas mengenai kejadian yang sudah dialami (Keraf, 2007, hlm. 136).

Satu hal atau benda disebut memiliki struktur benda kalau benda atau hal tersebut dibangun oleh bagian-bagian yang saling mempengaruhi secara fungsional. Struktur karangan narasi dapat dilihat dari komponen-komponen pembentuknya, salah satunya plot atau alur. Alur merupakan kerangka dasar yang penting dalam cerita. Alur terbagi ke dalam tiga bagian yaitu pembuka, perkembangan, dan penutup.

Bagian pembuka menyajikan situasi dasar. Bagian pembuka harus memiliki daya tarik untuk membaca agar dapat memahami kejadian-kejadian selanjutnya. Bagian perkembangan atau bagian tengah merupakan bagian utama dari karangan narasi. Bagian tengah merupakan bagian yang meningkatkan komplikasi dalam cerita. Bagian penutup merupakan bagian di mana pembaca merasa dapat melihat semua makna cerita. Bagian ini juga berupa bagian yang menunjukan struktur dan makna untuk mendapatkan fungsinya. (Keraf, 2007, hlm. 150-155). 
Bahan pengajaran membaca merupakan bahan ajar yang dilandasi oleh adanya teks atau karangan. Dari 16 karangan narasi yang disusun oleh murid kelas IV ditemukan 5 karangan yang relatif baik dan dapat dipakai bahan pengajaran membaca. Di bawah ini akan digunakan salah satu contoh karangan narasi yang dianggap cocok.

\section{KI\& KD Membaca Karangan Narasi}

KI : Memahami pengetahuan faktual dengan cara mengamati dan mencoba (mendengar, melihat, membaca) serta menanya berdasarkan rasa ingin tahu secara kritis tentang dirinya, makhluk ciptaan Tuhan, dan kegiatannya, dan benda - benda yang dijumpainya di rumah, sekolah, dan tempat bermain.

KD : Menggali isi teks narasi tentang menggapai cita - cita dengan kata katanya sendiri menjadi sebuah prosa tertulis.

\section{Tujuan Pangajaran Membaca Narasi}

Setelah kegiatan belajar mengajar selesai, murid dapat membaca dalam hati dan memahami isi bacaan. Kemampuan kosakata erat kaitannya dengan keterampilan membaca. Murid dapat memahami isi bacaan kalau murid memahami kosakatannya. Dari karangan narasi yang ditulis murid dipilih karangan narasi yang dianggap cocok untuk bahan pengajaran membaca. Pemilihan karangan narasi untuk bahan pengajaran membaca didasarkan pada tingkat interferensi dan alur karangan narasi. Karangan narasi yang dipilih yaitu yang memiliki tingkat interferensi yang paling rendah dan alur karangan yang sesuai dengan struktur alur karangan narasi. Dengan dipilihnya karangan narasi yang ditulis oleh murid untuk bahan pengajaran membaca, diharapkan mampu meningkatkan motivasi murid untuk belajar bahasa Sunda. Guru dapat menjelaskan karangan narasi murid menggunakan berbagai macam teknik pengajaran kosakata agar murid dapat memahami kata-kata dalam karangan narasi yang ditulis. Kemudian, murid dapat memahami kesalahan dalam karangan narasi yang ditulis dan memahami penerapan kata-kata dengan benar. Selain itu, diharapkan hal ini dapat menambah pengalaman belajar murid dan dapat menambah kekayaan kosakata bahasa Sunda murid.

\section{SIMPULAN}

Kosakata dalam karangan narasi murid sekolah dasar menunjukan kemampuan murid dalam menyatakan pengalaman dan pendirian dalam bentuk tulisan. Dari 16 karangan ditemukan 650 kata yang frekuensi pemakaianya sebanyak 2520 kata. Setelah dilakukan analisis mengenai jenis kosakata ditemukan data 216 kata dasar, 74 kata termasuk bentukan kata baru, dan 126 kata termasuk kata tugas. Menurut pendapat ahli, murid akan menguasai lebih banyak nomina daripada verba. Dari karangan narasi yang ditulis oleh murid sekolah dasar ditemukan katakata yang mengalami interferensi dari bahasa lain. Interferensi yang ditemukan yaitu interferensi dari bahasa Indonesia, bahasa Inggris, dan bahasa Arab. Dari karangan narasi yang ditulis oleh murid kelas IV relatif sesuai dengan perkembangan umur murid. Setelah dianalisis ditemukan data sebanyak 64 kata sesuai dengan perkembangan usia murid. Selain itu, terdapat kata-kata yang dianggap cocok untuk penutur dewasa. Kata-kata yang dianggap cocok untuk penutur dewasa sebanyak 10 kata. Karangan narasi yang ditulis oleh murid kelas IV bisa menjadi salah satu alternatif untuk bahan pengajaran membaca. Kemampuan kosakata erat hubungannya dengan keterampilan membaca. Dari 16 karangan narasi ada lima karangan yang dianggap cocok untuk bahan pengajaran membaca dilihat dari tingkat interferensi 
dan struktur alur karangan narasi yang ditulis oleh murid sekolah dasar.

\section{PUSTAKA RUJUKAN}

Alwasilah, A. Chaedar. (2002). Pokoknya Kualitatif. Bandung: PT. Kiblat Utama.

Dale, Edgar dkk.(1971). Techniques of Teaching Vocabulary. United States of America: Field Educational Publications Incorporated.

Husen, H. Akhlan \& Rahman. (1996). Perencanaan Pengajaran Bahasa. Jakarta: Departemen Pendidikan dan Kebudayaan Dirjen Dikdasmen Bagian Proyek Penataran Guru SLTP setara D-III.

Keraf, Gorys. (2007). Argumentasi dan Narasi. Jakarta: PT. Gramedia Pustaka Utama.

Kusmayati, Nurita Bayu. (2009). Penguasaan Kosakata Siswa dalam Pembelajaran Keterampilan Berbahasa dalam Jurnal Bahasa dan sastra dalam Perspektif pendidikan. Bandung: Jurusan Pendidikan Bahasa dan Sastra Indonesia FPBS UPI.

Resmini, Novi, Tatat Hartati. (2006). Kapita Selekta Bahasa Indonesia. Bandung: UPI Press.

Sudaryat, Yayat, spk. (2007). Tata Basa Sunda Kiwari. Bandung: YramaWidya.

Tarigan, Henry Guntur. (2011). Pengajaran Kosakata. Bandung: Angkasa

Tarigan, Henry Guntur. (2008). Membaca (sebagai suatu keterampilan berbahasa). Bandung: Angkasa.

\section{UCAPAN TERIMAKASIH}

Terimakasih penulis ucapkan kepada teman seperjuangan yang selalu memberikan semangat sehingga penelitian ini berhasil dimuat. 